\title{
Therapeutic potential and functional interaction of carfilzomib and vorinostat in T-cell leukemia/lymphoma
}

\author{
Minjie Gao ${ }^{1}$, Gege Chen ${ }^{1}$, Houcai Wang ${ }^{1}$, Bingqian $\mathrm{Xie}^{1}$, Liangning Hu${ }^{1}$, Yuanyuan \\ Kong $^{1}$, Guang Yang ${ }^{1}$, Yi Tao ${ }^{1}$, Ying Han ${ }^{1}$, Xiaosong Wu ${ }^{1}$, Yiwen Zhang ${ }^{1}$, Bojie Dai ${ }^{1,2}$, \\ Jumei Shi ${ }^{1}$ \\ ${ }^{1}$ Department of Hematology, Shanghai Tenth People's Hospital, Tongji University School of Medicine, Shanghai, China \\ ${ }^{2}$ College of Life Science and Technology, Tongji University, Shanghai, China \\ Correspondence to: Jumei Shi, e-mail: shijumei@tongji.edu.cn \\ Bojie Dai, e-mail: bojiedai@gmail.com
}

Keywords: carfilzomib, vorinostat, T-cell leukemia and lymphoma

Received: December 02, $2015 \quad$ Accepted: March 28, 2016

Published: April 09, 2016

\section{ABSTRACT}

We previously showed that the proteasome inhibitor carfilzomib and the histone deacetylase inhibitor (HDACI) vorinostat cooperated to induce cell apoptosis in one T-cell leukemia cell line in vitro, implying the possibility of the combination treatment of carfilzomib and vorinostat as a potential therapeutic strategy in human T-cell leukemia/lymphoma. Here we report that combination treatment of carfilzomib and vorinostat enhanced cell apoptosis and induced a marked increase in $\mathbf{G}_{\mathbf{2}}-\mathbf{M}$ arrest, reactive oxygen species (ROS) generation, and activated the members of mitogenactivated protein kinases (MAPK) family, including the stress-activated kinases JNK, p38MAPK, and ERK1/2. Carfilzomib/vorinostat-mediated apoptosis was blocked by the ROS scavenger $\mathrm{N}$-acetylcysteine (NAC). The JNK inhibitor SP600125 and the p38MAPK inhibitor SB203580 but not the MEK1/2 inhibitor U0126 significantly attenuated carfilzomib/vorinostat-induced apoptosis, suggesting that p38MAPK and JNK activation contribute to carfilzomib and vorinostat-induced apoptosis. This was further confirmed via short hairpin (shRNA) RNA knockdown of p38MAPK and JNK. Interestingly, the ROS scavenger NAC attenuated carfilzomib/vorinostatmediated activation of p38MAPK and JNK. However, p38MAPK shRNA but not JNK shRNA diminished carfilzomib/vorinostat-mediated ROS generation. In contrast, overexpression of p38MAPK significantly increased carfilzomib/vorinostat-mediated ROS generation, suggesting that an amplification loop exists between ROS and p38MAPK pathway. Combination treatment of carfilzomib and vorinostat enhanced their individual antitumor activity in both a human xenograft model as well as human primary T-cell leukemia/lymphoma cells. These data suggest the potential clinical benefit and underlying molecular mechanism of combining carfilzomib with vorinostat in the treatment of human T-cell leukemia/lymphoma.

\section{INTRODUCTION}

T-cell acute lymphoblastic leukemia and T-cell lymphoma are aggressive hematopoietic tumors. With the development of intensified chemotherapy, the prognosis of T-cell leukemia/lymphoma has gradually improved. However, the outcome of these patients with relapse and resistance remains extremely poor $[1,2]$. Therefore, further research is required to identify therapeutic targets to develop more effective and less toxic antitumor drugs. Multiple signaling pathways are involved in the pathogenesis and survival of T-cell malignancies, such as the dysregulation of NOTCH1 [3, 4], extracellular signalregulating kinase1/2 (ERK1/2) [5], phosphoinositide 3-kinase (PI3K)-AKT [6], c-jun N-terminal kinase (JNK) [7], p38 mitogen-activated protein kinase (p38MAPK) $[7,8]$, and Janus kinase/ signal transducers and activators of transcription (JAK/STAT) $[9,10]$. Yet much remains to be understood about the role of these signaling pathways in T-cell leukemia/lymphoma. 
Proteasome inhibitors are currently used as an effective approach to kill cancer cells which are resistant to conventional chemotherapy. Bortezomib is a first-in-class proteasome inhibitor used either alone or in combination with other agents in the treatment of multiple myeloma (MM) [11]. The preexistence or development of bortezomib resistance, however, has prompted the development of the second-generation proteasome inhibitor carfilzomib, which shows efficacy as either single agent or in combination with other agents against MM [12] and other cancers [13]. Carfilzomib has overcome bortezomib resistance in patients [12] and has been approved for treatment of MM [14].

Another class of drugs, histone deacetylase inhibitors (HDACIs), has also been shown to inhibit cell proliferation, induce differentiation and cell cycle arrest, and promote apoptosis in a wide range of hematological and solid malignancies. These inhibitors have been shown to inhibit cancer cell growth through both the inhibition of histones deacetylation and effects on non-histone proteins [15]. HDACIs alter expression in $2-10 \%$ of genes involved in biological processes [16]. Due to the multiple anticancer mechanisms of HDACIs, there is growing interest in exploring permutations of combined therapies in an attempt to maximize the antitumor effect with many of these having been evaluated in pre-clinical in vivo models and clinical trials [15]. HDACIs are well-tolerated in a variety of malignancies [15] and vorinostat is an HDACI that has been approved for the treatment of cutaneous T-cell lymphomas [17] making it an attractive candidate.

Synergy between the proteasome inhibitor bortezomib and HDACIs has been described in diverse malignant cell types [18-20], particularly those of hematopoietic origin [21-23], as well as in a number of cancers such as nasopharyngeal carcinoma [18], prostate cancer [24], glioblastoma [25], ovarian carcinoma [26], multiple myeloma [27], acute myeloid leukemia, myelodysplastic syndrome [23], and others. However, bortezomib use can be limited because of peripheral neuropathy and the existence and development of resistance [28]. Carfilzomib, a second-generation, irreversible, selective proteasome inhibitor, was found to be more potent than bortezomib in both MM cell line models and clinical samples [29, 30]. Importantly, carfilzomib had activity against bortezomibresistant cell lines and bortezomib-resistant primary cells $[28,31]$. Thus, the combination of carfilzomib with HDACIs, such as vorinostat, holds promise to be more efficacious and safer than the combination of bortezomib and HDACIs. This combination currently has only been reported in diffuse large-B-cell lymphoma and mantle cell lymphoma [32-33]. However, it has not been well investigated in T-cell leukemia/lymphoma. Our lab has previously observed that the combination has potentiated the apoptosis in Jurkat cell line [34]. Here, we further determined whether combined treatment of carfilzomib and vorinostat has enhanced antitumor activity in in vitro other T-cell leukemia/lymphoma cell lines and in vivo, and then identified the underlying molecular mechanism. Our results indicated that concurrent administration of carfilzomib and vorinostat enhanced their individual antitumor activity in both a human xenograft model as well as primary human T-cell leukemia/lymphoma cells, in association with the amplification loop between ROS generation and p38MAPK and with ROS-dependent JNK activation. Furthermore, combined treatment of carfilzomib and vorinostat is very well tolerated and only shows minimal toxicity. Collectively, these findings provide a rationale for using this combinatorial therapy in human T-cell leukemia/lymphoma.

\section{RESULTS}

\section{Carfilzomib and vorinostat effectively inhibited cell proliferation in T-cell leukemia/lymphoma cell lines}

To assess the combined effect of carfilzomib and vorinostat, we first evaluated proliferation by CCK- 8 assay in the T-cell leukemia and lymphoma cell lines MOLT4 and HuT 78, respectively, in the presence of either drug alone or their combination. At the concentration of less than $8.0 \mathrm{nM}$, carfilzomib only modestly inhibited proliferation in both cell lines. In contrast, cell proliferation was substantially inhibited when carfilzomib was combined with low amounts of vorinostat $(0.3$ or $0.4 \mu \mathrm{M})$ (Figure 1A). Similarly, vorinostat on its own was only marginally effective at inhibiting proliferation in both MOLT-4 and HuT78 cells, but exhibited marked inhibition of proliferation in combination with low concentrations of carfilzomib (5 or $6 \mathrm{nM}$ ) (Figure 1B). Median dose effect analysis of the interaction between carfilzomib $(2-10 \mathrm{nM})$ and vorinostat $(0.3$ or $0.4 \mu \mathrm{M})$ yielded combination index (CI) values substantially less than 1.0, denoting synergy (Figure 1C). To explore the combined effect over time, both cell lines were treated for various intervals with each drug alone or the combination. This resulted in the most pronounced synergistic effect at $48 \mathrm{~h}$ (Figure 1D). In order to test whether combined treatment of carfilzomib and vorinostat were also effective in cell lines which are resistant to bortezomib, MOLT-4-20BR and HuT 78-25BR bortezomib-resistant cells were generated. Bortezomibresistance did not abrogate the effect of carfilzomib and vorinostat, but did necessitate slightly higher concentrations ( $8 \mathrm{nM}$ with $0.5 \mu \mathrm{M}, 10 \mathrm{nM}$ with $0.5 \mu \mathrm{M}$, carfilzomib and vorinostat, respectively, at $48 \mathrm{~h}$ ) (Figure 1E). Together, these data demonstrate that the combination of carfilzomib and vorinostat is more effective against these T-cell leukemia/ lymphoma cell lines compared with either inhibitor alone.

\section{Combination treatment of carfilzomib and vorinostat induces more apoptosis in T-cell leukemia/lymphoma cell lines}

To explore whether the combination of carfilzomib and vorinostat induced more apoptosis, MOLT-4 and HuT 78 cells were incubated with carfilzomib (MOLT- $46 \mathrm{nM}$, 
HuT $788 \mathrm{nM}$ ) or/and vorinostat (MOLT-4 0.4 $\mu \mathrm{M}$, HuT $780.4 \mu \mathrm{M}$ ) for $48 \mathrm{~h}$ and cell apoptosis was analyzed by flow cytometry using Annexin V staining kit. Combination treatment resulted in a significant percentage of apoptotic cells, $59.1 \% \pm 4.6 \%$ in MOLT- 4 cells and $50.9 \% \pm 3.5 \%$ in HuT 78 cells respectively, whereas the percentage of apoptotic cells upon treatment with carfilzomib alone (MOLT-4 11.2\% \pm 1.8\%, HuT 78 11.0\% $\pm 1.9 \%$ ) or vorinostat alone (MOLT-4 13.5\% $\pm 1.8 \%$, HuT 78 $15.7 \% \pm 2.4 \%$ ) was considerably lower (Figure 2A). Cell apoptosis was further confirmed by caspase activation and PARP cleavage (Figure 2B). Using the fluorescent probe JC-1, a sensitive marker for mitochondrial membrane potential, combination treatment substantially reduced mitochondrial membrane potential in MOLT4 and HuT 78 cells compared to either carfilzomib or vorinostat alone (Figure 2C). Together these findings demonstrate that combination treatment of carfilzomib and vorinostat induces more apoptosis than either treatment alone.

\section{MAPK signaling pathways were modulated by combination treatment of carfilzomib and vorinostat}

Multiple signaling pathways were shown to be involved in the apoptosis of cancer cells induced by the combination of proteasomal and histone deacetylase inhibition, including the MAPK family $[33,35,36]$ and AKT [37]. As shown in Figure 3, treatment with carfilzomib alone resulted in activation of p38MAPK, JNK and ERK1/2 and the combination treatment potentiated the activation in both cell types. The combination treatment didn't change the phosphorylation of AKT (Figure 3). These data suggest that vorinostat potentiates the activation of $\mathrm{p} 38 \mathrm{MAPK}, \mathrm{JNK}$ and ERK1/2 by carfilzomib.

\section{Carfilzomib in combination with vorinostat potentiates $\mathrm{G}_{2}-\mathrm{M}$ arrest}

To study the effect of carfilzomib and vorinostat on the cell cycle, cells were incubated with carfilzomib (MOLT-4 $6 \mathrm{nM}$, HuT $788 \mathrm{nM}$ ) and/or vorinostat (MOLT$40.4 \mu \mathrm{M}$, HuT $780.4 \mu \mathrm{M}$ ) for $24 \mathrm{~h}$, and cell cycle was analysed by flow cytometry. As shown in Table 1, cells treated with vorinostat alone slightly increased the $\mathrm{S}$ phase population in both cell lines. Cells treated with carfilzomib alone accumulated in $\mathrm{G}_{2}-\mathrm{M}$ phase of the cell cycle in both cell lines. While cells were treated with the combination of carfilzomib with vorinostat, there was a highly significant increase in the $\mathrm{G}_{2}-\mathrm{M}$ phase population, compared to treatment with carfilzomib alone $(n=3$, $P<0.005)$.

\section{Combination treatment induced ROS generation and the increase of ROS generation played a critical role in the induction of apoptosis}

Increased reactive oxygen species (ROS) levels have previously been shown to play an important role in the induction of apoptosis resulting from the combinatorial treatment of a proteasome inhibitor with an HDACI $[38,39]$, we next evaluated ROS production in treated MOLT-4 cells by flow cytometry using DCFH-DA. Treatment with either carfilzomib or vorinostat alone slightly increased the level of ROS. However, the combination of carfilzomib with vorinostat markedly increased ROS generation (Figure 4A). Increases in ROS were observed starting from the treatment of $12 \mathrm{~h}$, with maximal increase at $24 \mathrm{~h}$ (Figure 4B). Importantly, the ROS scavenger N-acetylcysteine (NAC) largely abrogated ROS generation (Figure 4A) and dramatically attenuated cell apoptosis induced by the combination treatment (Figure 4C). These findings indicate that the induced apoptosis by combination treatment of carfilzomib with vorinostat is mediated through the increase of ROS in T-cell leukemia/ lymphoma cells.

\section{p38MAPK and JNK activation contribute to carfilzomib and vorinostat-induced apoptosis}

To determine whether the activation of ERK1/2, p38MAPK, and JNK is involoved in apoptosis induced by combination treatment of carfilzomib and vorinostat, cells were pretreated with $10 \mu \mathrm{M}$ of the inhibitors U0126 (ERK1/2), SB203580 (p38MAPK), and SP600125 (JNK) for two hours prior to combination treatment. JNK pathway inhibitor SP600125 and p38MAPK pathway inhibitor SB203580 partially protected cells from carfilzomib and vorinostat-induced apoptosis (Figure 5A). However, ERK1/2 pathway inhibitor U0126 did not attenuate cell apoptosis induced by combination treatment (Figure 5A). To further explore the impact of the p38MAPK and JNK pathways on the sensitivity of T-cell leukemia/lymphoma cells to the combination treatment, we examined the effect of the combined inhibitors in the MOLT-4 cells with different levels of p38MAPK or JNK. MOLT-4 cells were stably transduced with the lentivirus encoding either p38MAPK shRNA or JNK shRNA and displayed a clear reduction in p38MAPK or JNK expression, respectively, compared with cells transduced with scrambled sequence controls (Figure 5B and 5D). p38MAPK shRNA cells were significantly less sensitive than control cells to carfilzomib/ vorinostat lethality (Figure 5B). Notably, p38MAPK shRNA cells attenuated carfilzomib/vorinostat-mediated p38MAPK activation and PARP cleavage compared with control cells (Figure 5C). Similar results were observed in JNK shRNA cells (Figure 5D and 5E). Together, these data show that activation of $\mathrm{p} 38 \mathrm{MAPK}$ and JNK contributes 
Table 1: Combination of carfilzomib with vorinostat induced $G_{2}-M$ arrest

\begin{tabular}{|c|c|c|c|c|}
\hline Cell cycle & Control & CFZ & VOR & CFZ and VOR \\
\hline \multicolumn{5}{|l|}{ MOLT-4 } \\
\hline $\mathrm{G}_{0} \mathrm{G}_{1}$ & $44.9+3.1$ & $22.8+1.7$ & $44.8+2.7$ & $35.8+3.1$ \\
\hline $\mathrm{G}_{2}-\mathrm{M}$ & $12.3+1.5$ & $20.2+2.1 * *$ & $6.8+1.7$ & $35.3+3.6^{\dagger}$ \\
\hline S & $42.7+2.6$ & $57.1+3.1$ & $48.3+2.3$ & $29.0+4.9$ \\
\hline \multicolumn{5}{|l|}{ HuT 78} \\
\hline $\mathrm{G}_{0} \mathrm{G}_{1}$ & $54.3+2.7$ & $44.2+1.7$ & $54.0+2.7$ & $41.2+1.6$ \\
\hline $\mathrm{G}_{2}-\mathrm{M}$ & $10.1+1.4$ & $16.7+1.3^{* *}$ & $6.3+1.2$ & $38.0+2.6^{\dagger}$ \\
\hline $\mathrm{S}$ & $35.6+3.7$ & $39.2+0.7$ & $39.7+3.6$ & $20.8+1.0$ \\
\hline
\end{tabular}

A

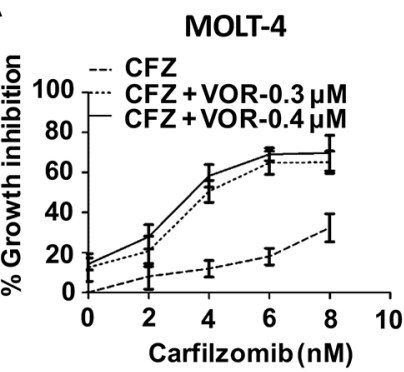

C

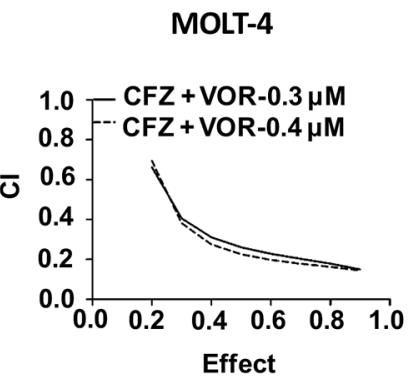

E

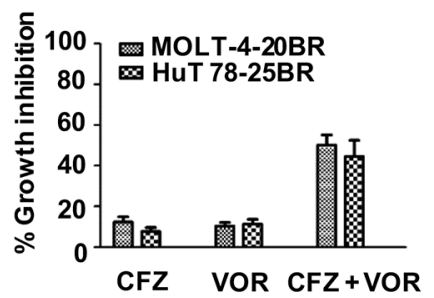

HuT 78

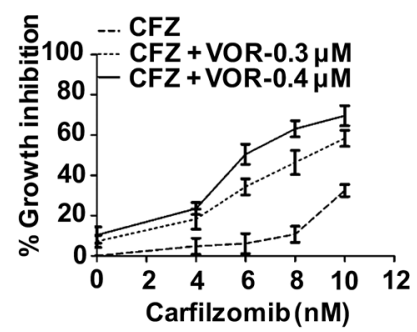

HuT 78

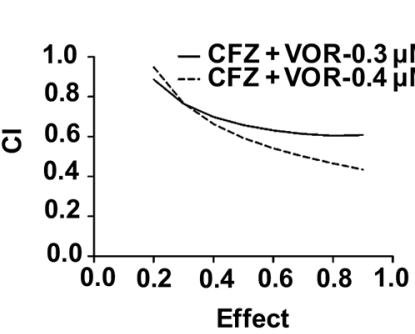

MOLT-4

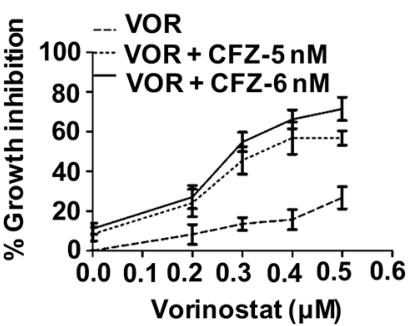

MOLT-4

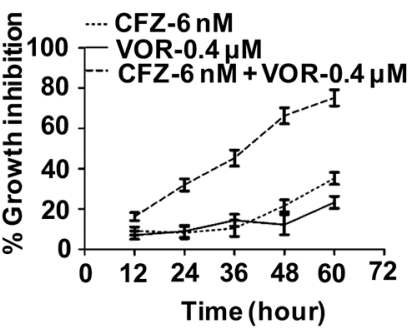

HuT 78

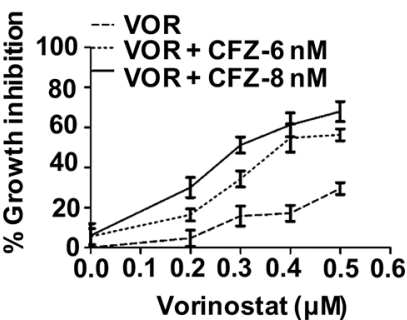

HuT 78

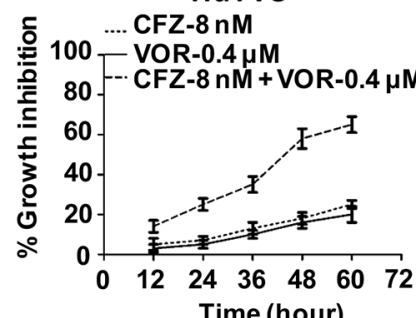

Figure 1: Carfilzomib and vorinostat cooperatively inhibited cell proliferation in T-cell leukemia/lymphoma cell lines. (A) Cells were treated with various carfilzomib concentrations (MOLT-4 2.0-8.0 nM, HuT 78 4.0-10.0 nM) and fixed vorinostat concentrations $(0.3$ or $0.4 \mu \mathrm{M})$ for $48 \mathrm{~h}$, then cell viability was monitored by CCK-8. (B) Cells were treated with various vorinostat concentrations $(0.2-0.5 \mu \mathrm{M})$ and fixed carfilzomib concentrations (MOLT-4 5 or $6 \mathrm{nM}$, HuT 786 or $8 \mathrm{nM}$ ) for 48 h, then cell viability was monitored by CCK-8. (C) CI values were calculated based on median-effect principle. CI values less than 1.0 denote synergistic interactions. Results are the means of three experiments. (D) Cells were treated with carfilzomib (MOLT-4 $6 \mathrm{nM}$, HuT $788 \mathrm{nM}$ ) or/and vorinostat (MOLT-4 $0.4 \mu \mathrm{M}$, HuT $780.4 \mu \mathrm{M}$ ) for the indicated intervals, then cell viability was monitored by CCK-8. (E) Cells were treated with carfilzomib (MOLT-4-20BR $8 \mathrm{nM}$, HuT 78-25BR $10 \mathrm{nM}$ ) or/and vorinostat (MOLT-4-20BR 0.5 $\mu$ M, HuT 78-25BR 0.5 $\mu$ M) for $48 \mathrm{~h}$, then cell viability was monitored by CCK-8. CFZ, carfilzomib; VOR, vorinostat. 
to cell apoptosis induced by the combination treatment of carfilzomib and vorinostat.

\section{The relationship between ROS and the pathways of p38MAPK and JNK}

Previous studies have shown that oxidative stress can activate MAPK signaling pathways [40]. We next examined whether the activity of p38MAPK and JNK is regulated by ROS. The ROS inhibitor NAC decreased the phosphorylation of p38MAPK and JNK in MOLT-4 cells (Figure 6A). This result may implicate that p38MAPK and $\mathrm{JNK}$ act as a downstream effector of ROS. We further explored whether a feedback mechanism underlies between ROS and the cell signaling of p38MAPK and JNK. Compared to scrambled control cells, p38MAPK shRNA cells significantly diminished carfilzomib/vorinostatmediated ROS generation (Figure 6B). However, the increase in carfilzomib/vorinostat-mediated ROS generation was similar in scrambled control and JNK shRNA cells (Figure 6C). Furthermore, overexpression of p38MAPK significantly increased carfilzomib/vorinostat-mediated ROS generation (Figure 6D), suggesting that an amplification loop exists between ROS and the p38MAPK pathway.

\section{The combination of carfilzomib with vorinostat inhibits tumor growth in a human xenograft model}

We next assessed the functional interactions between carfilzomib and vorinostat in vivo. Nude mice were inoculated in the flank with $5 \times 10^{6}$ MOLT-4 cells. After tumors were visible, mice were administered $2.0 \mathrm{mg} / \mathrm{kg}$ carfilzomib (i.v., days 1, 2, 8, 9, 15 and 16) with or without $40 \mathrm{mg} / \mathrm{kg}$ vorinostat (i.p., day 1, 2, 3, 8, 9, 10, 15, 16 and 17). As shown in Figure 7A, carfilzomib or vorinostat alone slightly inhibited tumor growth. However combination treatment resulted in potent inhibition of tumor growth compared to single inhibitor treatment. Moreover,
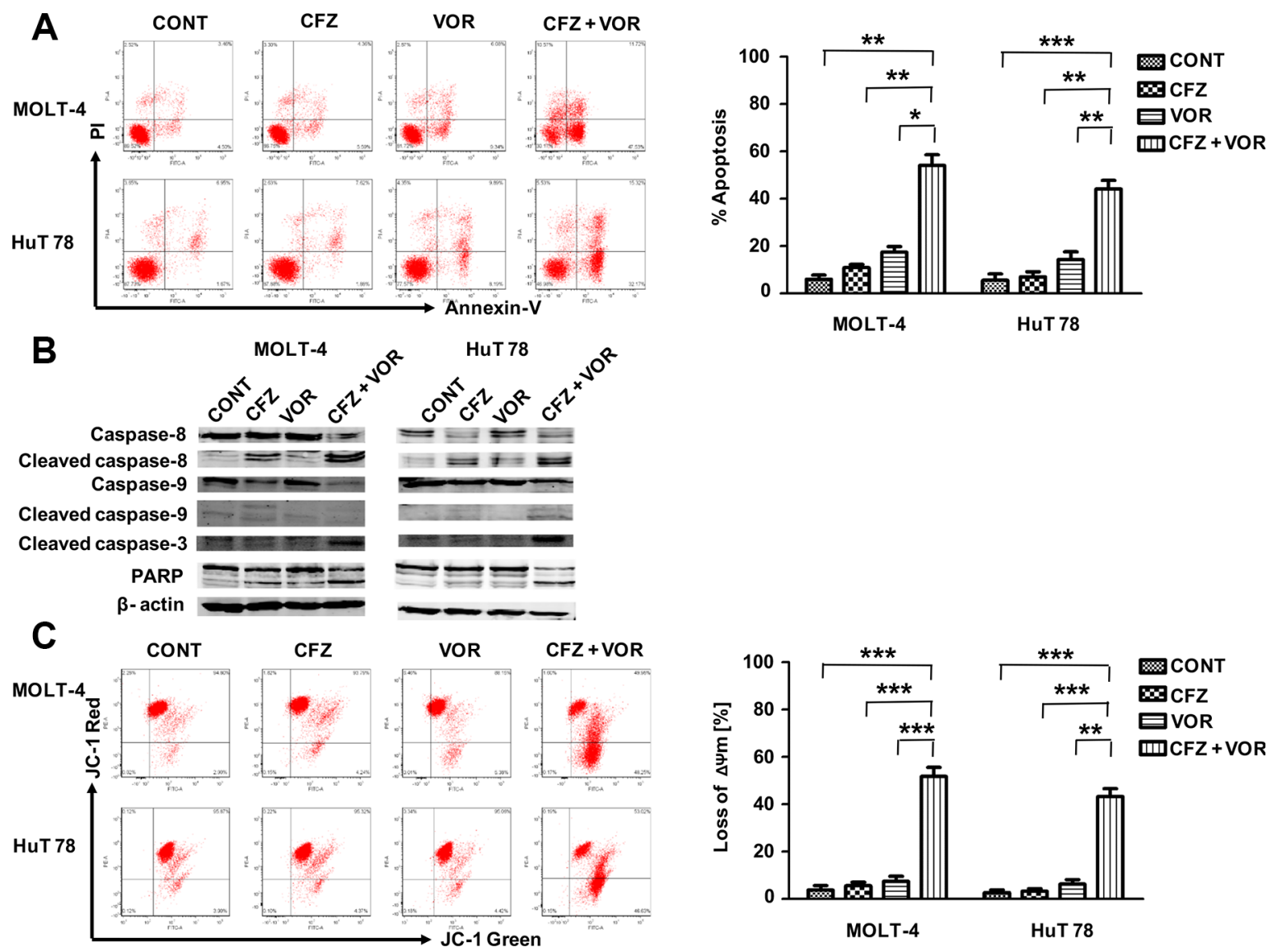

Figure 2: Combination treatment of carfilzomib and vorinostat enhanced apoptosis in T-cell leukemia/lymphoma cell lines. (A) Cells were treated with carfilzomib (MOLT-4 $6 \mathrm{nM}$, HuT $788 \mathrm{nM}$ ) or/and vorinostat (MOLT-4 0.4 $\mu \mathrm{M}$, HuT $780.4 \mu \mathrm{M}$ ) for $48 \mathrm{~h}$, then cell apoptosis was monitored by Annexin V/PI staining. Columns represent the average percent of Annexin V positive cells from three independent experiments, which are shown as the mean \pm SD. (B) After treatment as in A, the expression of caspase- 8 , cleaved caspase-8, caspase-9, cleaved caspase-9, cleaved caspase-3 and PARP were monitored by western blot. (C) After $24 \mathrm{~h}$ of drug exposure as in panel A, stained with JC-1 dye, mitochondrial membrane potential was detected by flow cytometry. Only JC-1 green positive (lower right quadrant) cells were analyzed for the loss of mitochondrial membrane potential. Columns represent the average percent of only JC-1 green positive cells from three independent experiments, which are shown as the mean $\pm \mathrm{SD}$. CFZ, carfilzomib; VOR, vorinostat; $\Delta \Psi \mathrm{m}$, mitochondrial membrane potential. * represent $p<0.05 ; * *$ represent $p<0.01 ; * * *$ represent $p<0.001$. 


\section{MOLT-4 HuT 78}

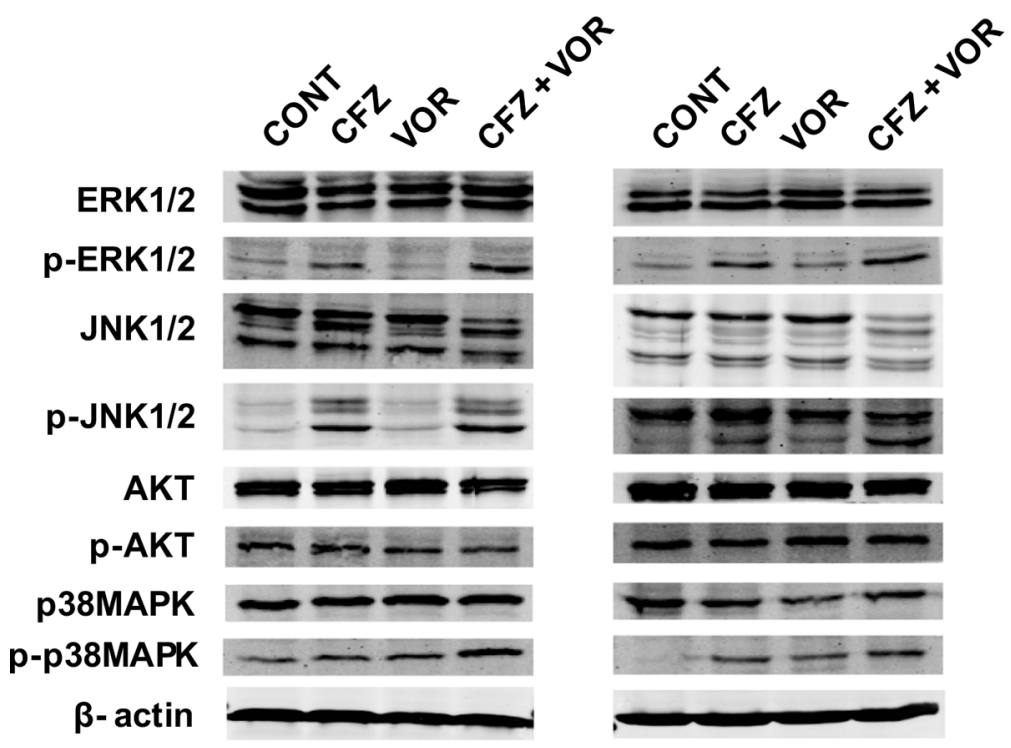

Figure 3: MAPK signaling pathways are mediated by combination treatment of carfilzomib and vorinostat. Cells were treated with carfilzomib (MOLT-4 $6 \mathrm{nM}$, HuT $788 \mathrm{nM}$ ) or/and vorinostat (MOLT-4 $0.4 \mu \mathrm{M}$, HuT $780.4 \mu \mathrm{M}$ ) for $48 \mathrm{~h}$, then the expression of phospho (p)-AKT, AKT, p-JNK, JNK, p-ERK1/2, ERK1/2, p-p38MAPK and p38MAPK were monitored by western blot. CFZ, carfilzomib; VOR, vorinostat.

A

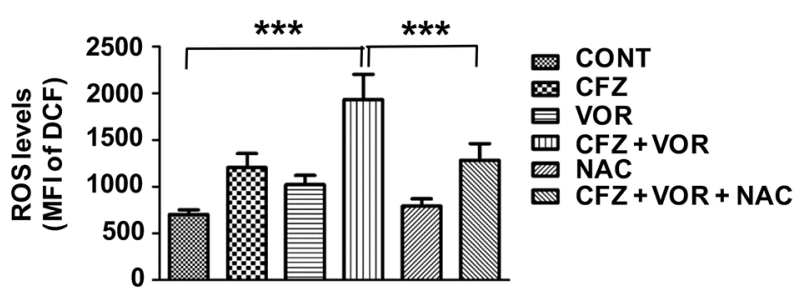

C

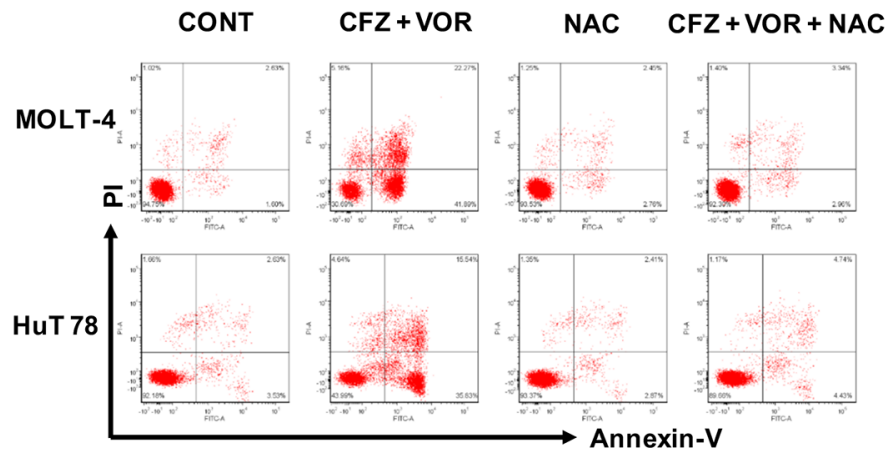

B

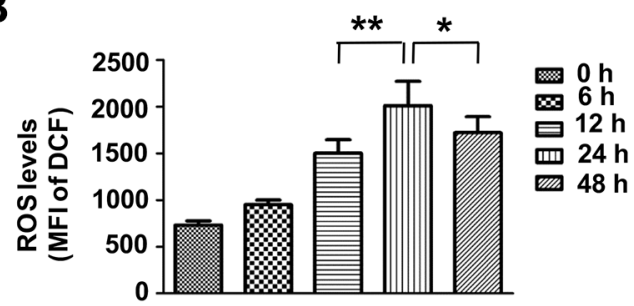

Figure 4: Combination treatment of carfilzomib and vorinostat induced ROS generation and induced apoptosis by the combination treatment is blocked by the ROS inhibitor. (A) MOLT- 4 cells were pre-incubated with or without 10 mM NAC for $3 \mathrm{~h}$ and then treated with carfilzomib $(6 \mathrm{nM})$ or/and vorinostat $(0.4 \mu \mathrm{M})$ for $24 \mathrm{~h}$, then the level of ROS was detected by flow cytometry using DCFH-DA. (B) MOLT-4 cells were treated with carfilzomib $(6 \mathrm{nM})$ and vorinostat $(0.4 \mu \mathrm{M})$, then the level of ROS was detected at various intervals by flow cytometry using DCFH-DA. (C) Cells were pre-incubated with or without $10 \mathrm{mM} \mathrm{NAC}$ for $3 \mathrm{~h}$ and then treated with carfilzomib (MOLT-4 $6 \mathrm{nM}$, HuT $788 \mathrm{nM}$ ) and vorinostat (MOLT-4 $0.4 \mu \mathrm{M}$, HuT $780.4 \mu \mathrm{M}$ ) for $48 \mathrm{~h}$, then cell apoptosis was monitored by Annexin V/PI staining. Columns represent the average percent of Annexin V positive cells from three independent experiments, which are shown as the mean $\pm \mathrm{SD}$. CFZ, carfilzomib; VOR, vorinostat. * represent $p<0.05$; **represent $p<0.01$; *** represent $p<0.001$. 
body weight loss was not observed in any treatment group (Figure 7B). TUNEL assay showed that combination treatment resulted in a pronounced increase of cell apoptosis compared to control and single inhibitor treatment (Figure 7C). Western blot analysis showed that combination treatment enhanced the phosphorylation of p38MAPK and JNK, and PARP cleavage compared to control and single inhibitor treatment (Figure 7D), which is consistent with in vitro results. Together, these results show that combination treatment with carfilzomib and vorinostat results in enhanced antitumor activity in vivo and is well-tolerated in animals.

\section{Combination treatment of carfilzomib and vorinostat induces cell apoptosis in human primary T-cell leukemia/lymphoma cells}

We wish the combination treatment of carfilzomib and vorinostat will be a potential candidate treatment strategy for human primary T-cell leukemia/lymphoma. Next, we examined the effect of the combination treatment in human primary T-cell leukemia/lymphoma cells.

Combination treatment with $10 \mathrm{nM}$ carfilzomib and $0.5 \mu \mathrm{M}$ vorinostat (48 h) was markedly cytotoxic to cells from three primary T-cell leukemias and one primary T-cell lymphoma (Figure 8A). Parallel studies were performed in normal $\mathrm{T}$ lymphocytes from human peripheral blood, $\mathrm{CD} 34^{+}$cells from human cord blood, or peripheral stem cell collection products in order to check the toxicity of the inhibitors. Normal hematopoietic cells were unresponsive to the combination treatment with $10 \mathrm{nM}$ carfilzomib and $0.5 \mu \mathrm{M}$ vorinostat. Moreover, individual and combination exposure to very high concentrations of carfilzomib and vorinostat $(80 \mathrm{nM}$ with $5 \mu \mathrm{M}$, respectively) resulted in relatively modest lethality toward these normal hematopoietic cells (Figure 8B-8D). These results are consistent with our xenograft data and further support that the combination treatment of carfilzomib and vorinostat potentiates their individual antitumour activity in human T-cell leukemia/lymphoma.

\section{B}

MOLT-4

D

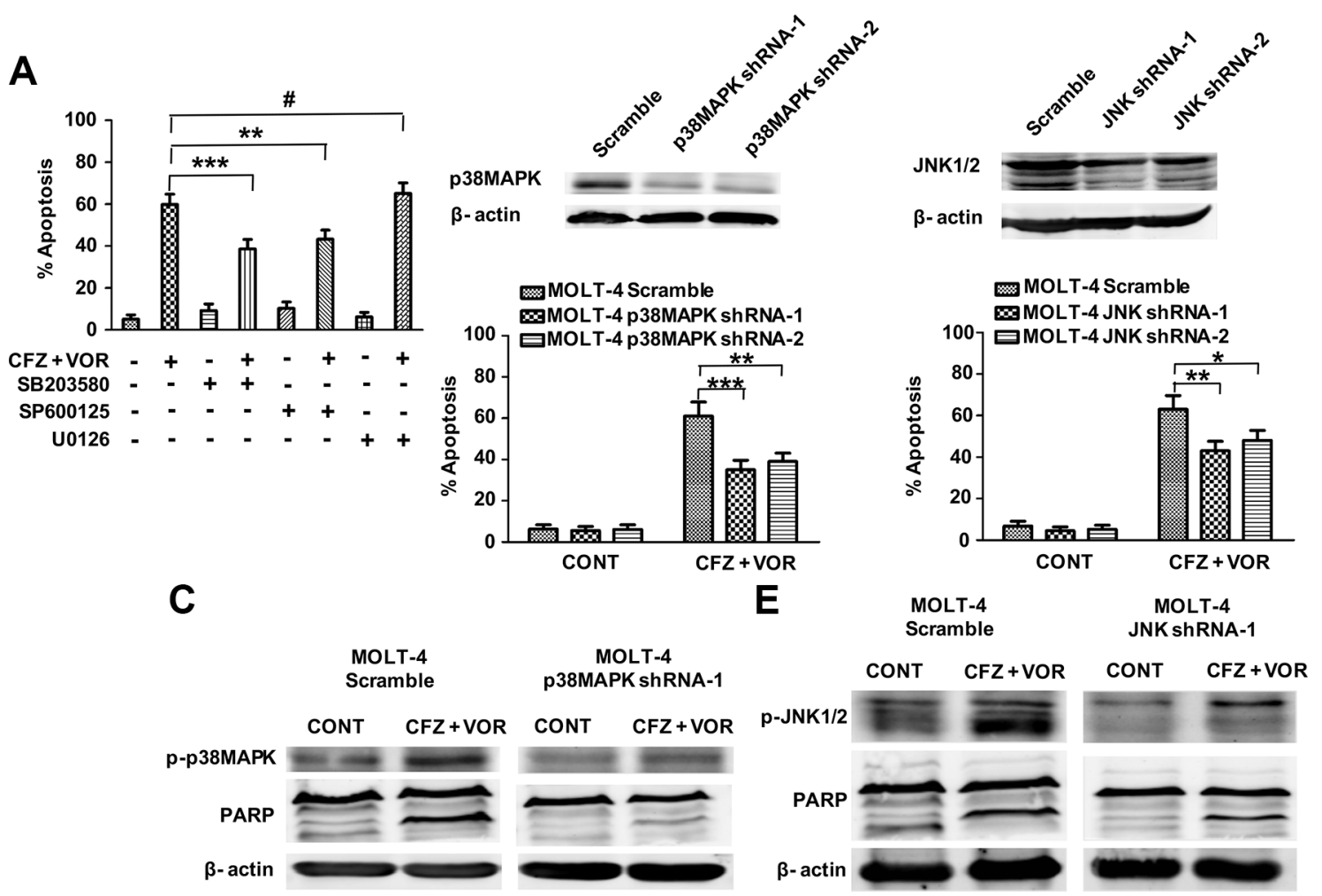

Figure 5: The activation of p38MAPK and JNK contribute to carfilzomib and vorinostat-induced apoptosis. (A) Pretreatment with U0126, SB203580, and SP600125 (10 $\mu \mathrm{M}$ each) for $2 \mathrm{~h}$, after which MOLT-4 cells were treated with $6 \mathrm{nM}$ carfilzomib or/and_0.4 $\mu \mathrm{M}$ vorinostat for $48 \mathrm{~h}$, then cell apoptosis was monitored by Annexin V/PI staining. (B) MOLT-4 cells stably expressing p38MAPK shRNA or scrambled sequence were treated with $6 \mathrm{nM}$ carfilzomib or/and_0.4 $\mu \mathrm{M}$ vorinostat for $48 \mathrm{~h}$, then cell apoptosis was monitored by Annexin V/PI staining. Inset: Relative expression of p38MAPK protein in MOLT-4 cells stably expressing p38MAPK shRNA and scrambled sequence. (C) After treatment as in B, the expression of p-p38MAPK and PARP proteins was monitored by western blot. (D) MOLT-4 cells stably expressing JNK shRNA or scrambled sequence were treated as in B, then cell apoptosis was monitored by Annexin V/PI staining. Inset: Relative expression of JNK protein in MOLT-4 cells stably expressing JNK shRNA and scrambled sequence. (E) MOLT-4 cells stably expressing JNK shRNA or scrambled sequence were treated as in B, and then the expression of JNK and PARP proteins was monitored by western blot. * represent $p<0.05$; ** represent $p<0.01$; *** represent $p<0.001$; ${ }^{*}$ represent $p>0.05$. 


\section{DISCUSSION}

The results of our present study provide evidence that carfilzomib and vorinostat cooperate to kill human T-cell leukemia/lymphoma cells in vitro and in vivo. This study was prompted by several considerations. First, synergistic interactions between bortezomib and vorinostat in several types of tumor cells, including hematopoietic cells, have been described. However, bortezomib efficacy can be limited because of peripheral neuropathy and the existence and development of resistance [28]. Second, carfilzomib is an irreversible proteasome inhibitor, which is active in bortezomib-resistant tumor cells in vitro and in patients with bortezomib-resistant disease. The combination of carfilzomib with vorinostat holds promise to be more efficacious and safer than the combination of bortezomib and vorinostat. Third, the combination of carfilzomib with vorinostat has been scarcely explored and currently has only been described in diffuse large-B-cell lymphoma, mantle cell lymphoma, and recently by our lab in one $\mathrm{T}$ cell leukemia cell line in vitro.

While either carfilzomib or vorinostat induce ROS generation, combination treatment enhances ROS generation considerably. Notably, cell apoptosis induced by the combination treatment was almost completely blocked by the ROS inhibitor NAC, suggesting that the induced apoptosis by the combination treatment is mediated through ROS. Previous studies have implicated increased ROS in the lethal combination of proteasome inhibition with HDACIs in many tumor cells, such as malignant human glioma cells [41], mantle cell lymphoma cells [42], cutaneous $\mathrm{T}$ cell lymphoma [43], leukemia cells [39] and non-small cell lung cancer cells [44]. Our findings are consistent with these and further indicate that ROS played an important functional role in the functional interaction between carfilzomib and vorinostat.

The activation of MAPK signaling pathway has been critical for a variety of toxic stimuli in the induction of apoptosis. JNK activation was previously observed in diffuse large-B-cell lymphoma (DLBCL) cells exposed to carfilzomib and HDACIs [33] and multiple myeloma cells exposed to bortezomib and NPI-0052 [45]. The activation of p38MAPK has resulted from synergy between bortezomib and valproic acid in leukemia cells [23] and between bortezomib and SAHA in cutaneous $\mathrm{T}$ cell lymphoma [43]. In keeping with those findings, we found that exposure of MOLT-4 and HuT 78 cells to

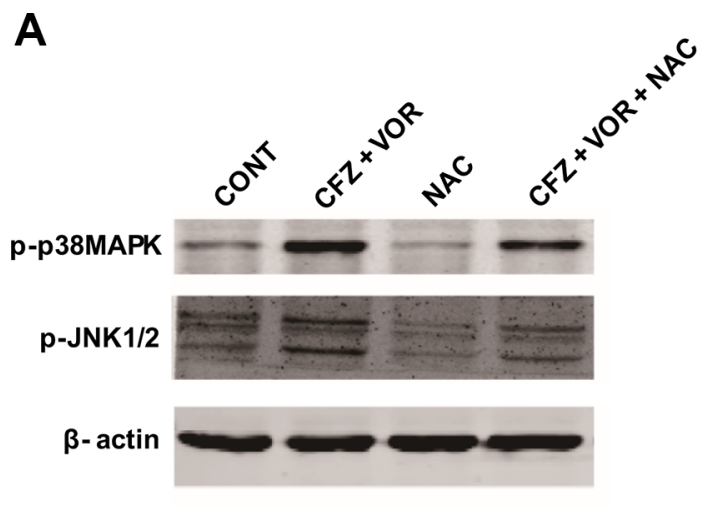

B
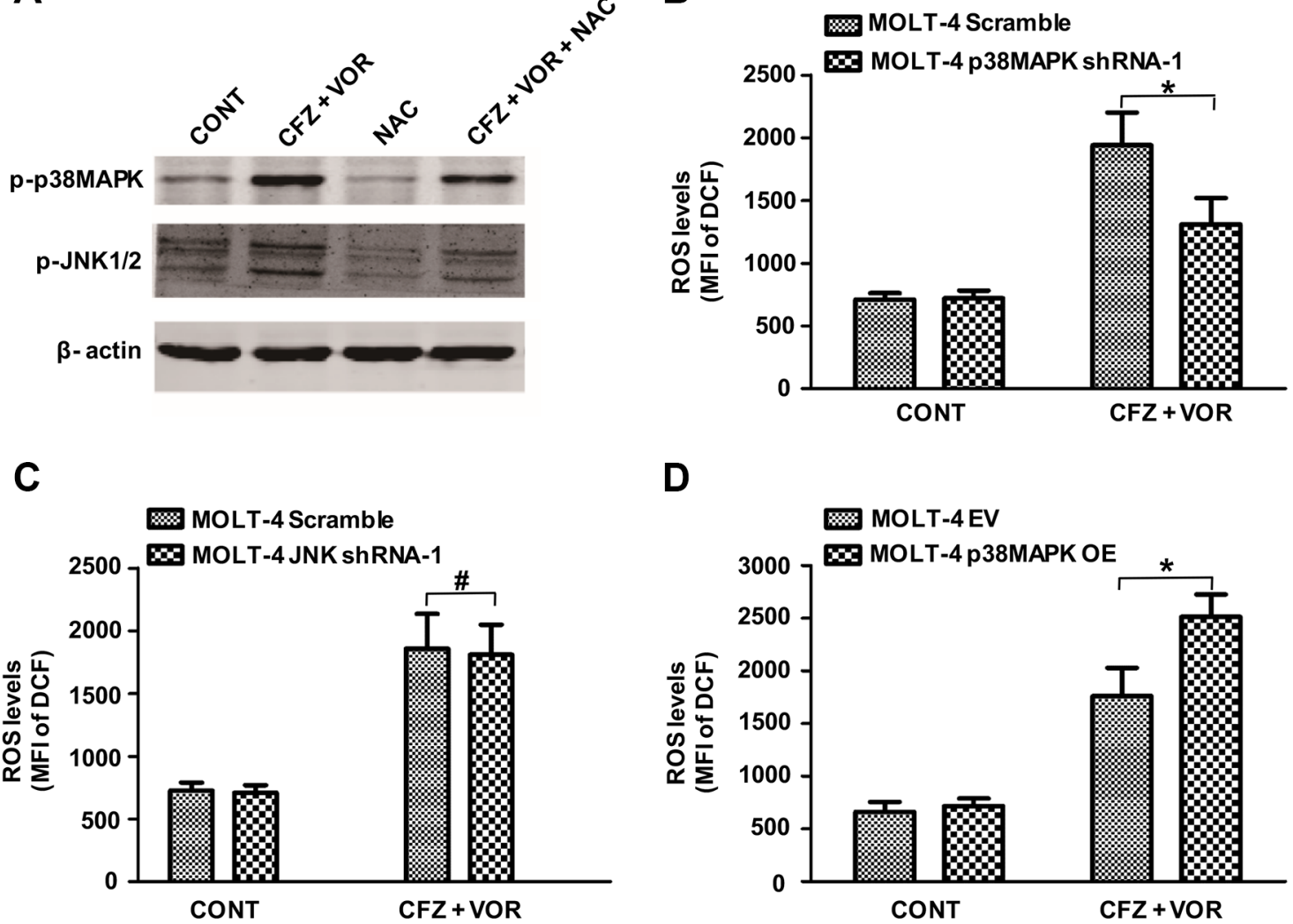

Figure 6: An amplification loop exists between ROS and p38MAPK pathway but not JNK pathway. (A) MOLT-4 cells were pre-incubated with or without $10 \mathrm{mM} \mathrm{NAC}$ for $3 \mathrm{~h}$ and then treated with carfilzomib $(6 \mathrm{nM})$ and vorinostat $(0.4 \mu \mathrm{M})$ for $48 \mathrm{~h}$, then the expression of p-p38MAPK and p-JNK proteins was monitored by western blot. (B) MOLT-4 cells stably expressing p38MAPK shRNA or scrambled sequence were treated with $6 \mathrm{nM}$ carfilzomib and $0.4 \mu \mathrm{M}$ vorinostat for $48 \mathrm{~h}$, then the level of ROS was detected using DCFHDA. (C) MOLT-4 cells stably expressing JNK shRNA or scrambled sequence were treated as in B, then the level of ROS was detected using DCFH-DA. (D) MOLT-4 cells transfected with plasmid DNA containing p38MAPK or empty vector were treated as in B, then the level of ROS was detected using DCFH-DA. * represent $p<0.05 ;{ }^{*}$ represent $p>0.05$. 
carfilzomib and vorinostat activated p38MAPK and JNK. Further, pharmacologic or genetic JNK or p38MAPK inhibition significantly blocked carfilzomib/vorinostatinduced lethality, indicating that JNK and p38MAPK play a functional role in cell apoptosis. We also observed that ERK1/2 was activated in MOLT-4 and HuT 78 cells exposed to carfilzomib and vorinostat. Activation of ERK1/2 has been shown to be a mediator of antiapoptotic and prosurvival actions in numerous cancer model systems [5]. Previous studies reported that coadministration of the MEK inhibitor sensitizes tumor cells and human tumor xenograft models to HDACIs, suggesting that ERK1/2 inhibition is a requirement for optimal HDACI effects [46-48]. In our study, combination treatment not only failed to result in lowered levels of p-ERK1/2 in either cell line tested, but also carfilzomib alone modestly activated ERK1/2 levels and this effect was enhanced by vorinostat, indicating that inhibition of the ERK1/2 pathway is not an absolute requirement for the action of HDACIs. It has been observed that prolonged activation of Raf/MEK/MAPK pathway can exert a pro-apoptotic effect in a manner that depended upon the cellular context [49]. Dasmahapatra et al. $[32,33]$ found, however, that phosphorylation level of ERK1/2 is high in DLBCL cell lines treated by combination of carfilzomib with vorinostat, but phosphorylation level of ERK1/2 is low in Mantle cell lines treated by combination of carfilzomib with vorinostat. Although both are B

A

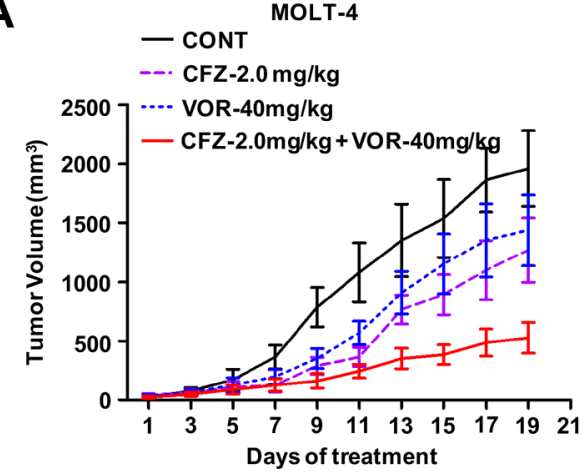

lymphoma cells, the activation of ERK1/2 was different between the two cell types under identical conditions, suggesting that the involvement of ERK $1 / 2$ is even cancer subtype dependent. We further targeted ERK1/2 but failed to attenuate carfilzomib/vorinostat lethality, suggesting that although ERK1/2 pathway is a target of these drugs, it is not required to mediate their apoptosis effects.

It has been described that the activation of MAPK signaling pathway was at least in part through oxidative stress caused by increased ROS [40]. In keeping with those findings, NAC inhibits the activation of p38 and JNK. Interestingly, genetic p38MAPK inhibition diminished carfilzomib/vorinostat-mediated ROS generation. However, genetic JNK inhibition didn't exert similar effect. Furthermore, overexpression of p38MAPK significantly increased carfilzomib/vorinostat-mediated ROS generation. Thus, we propose that an amplification loop exists between ROS and p38MAPK pathway. The activation of $\mathrm{p} 38 \mathrm{MAPK}$ pathway serves to amplify oxidative injury caused by increased ROS and, by extension, the apoptotic response.

Several lines of evidence show that combination of carfilzomib with vorinostat preferentially targets transformed cells versus normal hematopoietic cells [32, 33]. Our findings demonstrate that the combination of carfilzomib with vorinostat induced pronounced apoptosis toward both cultured and primary T-cell leukemia/lymphoma cells but exhibited minimal toxicity in normal hematopoietic
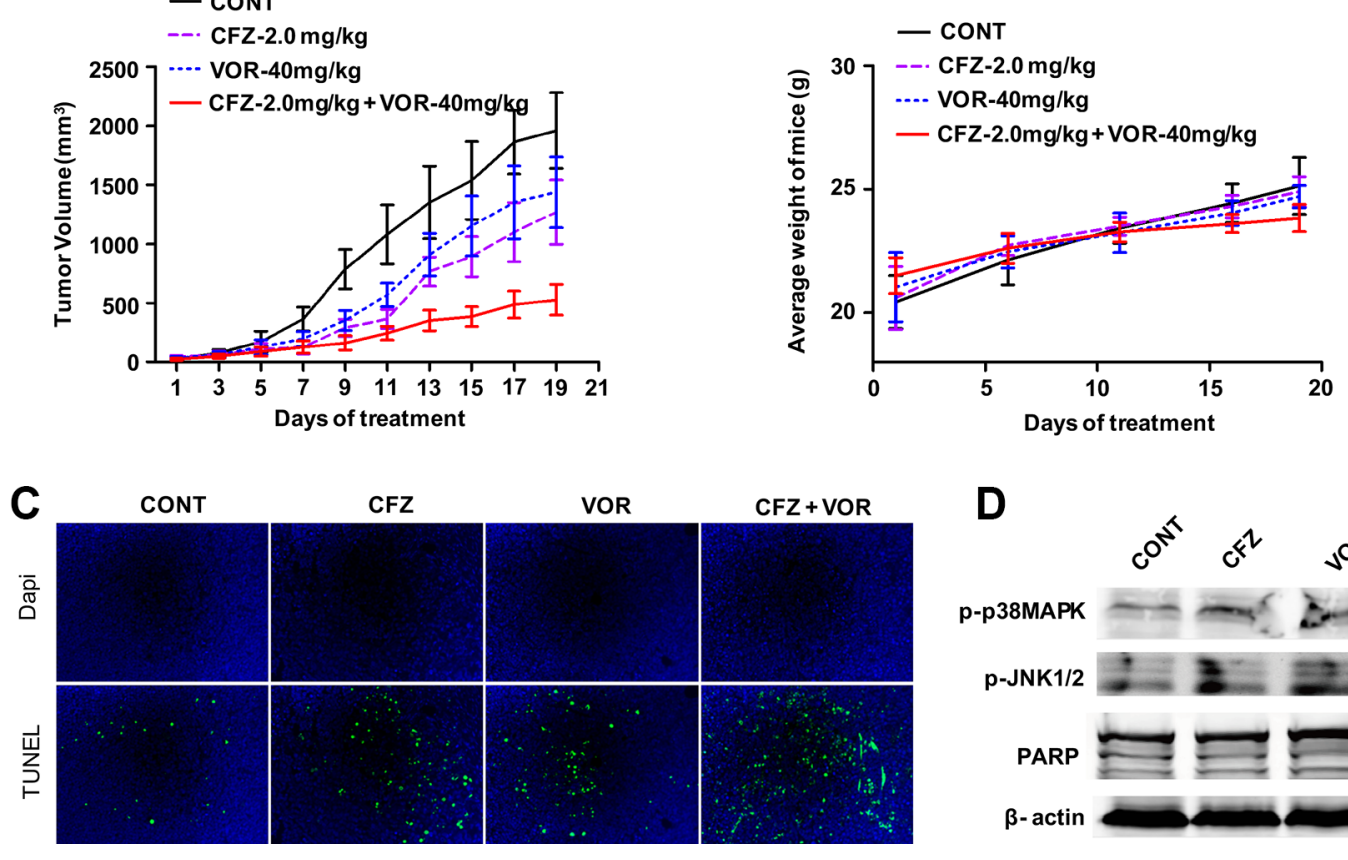

MOLT-4

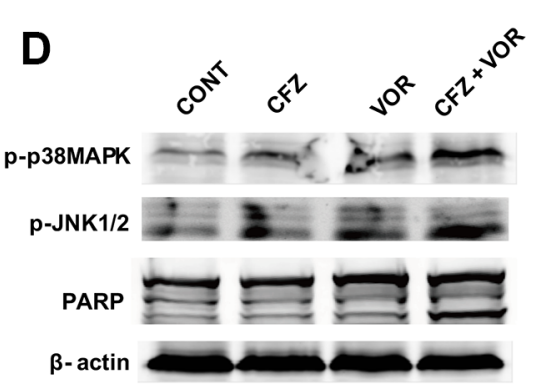

Figure 7: The combination of carfilzomib with vorinostat inhibits tumor growth in a human xenograft model. (A) Nude mice (4-6 weeks old) were injected subcutaneously with $5 \times 10^{6}$ MOLT-4 cells into the right flank. After tumors were visible, the mice received indicated doses carfilzomib with or without vorinostat as described in "Animal studies". Tumor volume was measured every other day with calipers and calculated using the formula $0.5 \times \mathrm{a} \times \mathrm{b}^{2}$ in millimeters. Results represent the Mean $\pm \mathrm{SD}$. (B) The body weight of mice after treatment was measured twice every week. Results represent the Mean \pm SD. (C) Sections from tumor samples per group were stained with FITC-dUTP as described in materials and methods $(\times 200)$. (D) Tumor samples were homogenized and lysed. The extracted proteins were probed with western blot for p-p38MAPK, p-JNK and PARP proteins. Each lane was loaded with $30 \mu \mathrm{g}$ of protein. The $\beta$-actin was used as an internal control. 
cells. These findings reinforce the notion that this regimen displays minimal toxicity toward normal hematopoietic cells and selectively target transformed cells.

We examined the in vivo effect of carfilzomib and vorinostat in a human xenograft model. Our finding suggested that $2.0 \mathrm{mg} / \mathrm{kg}$ carfilzomib by itself modestly inhibited tumor growth, whereas $40 \mathrm{mg} / \mathrm{kg}$ vorinostat by itself had little effect on tumor growth. However, combination of $2.0 \mathrm{mg} / \mathrm{kg}$ carfilzomib with $40 \mathrm{mg} /$ $\mathrm{kg}$ vorinostat markedly inhibited tumor growth in the xenograft model. These results may have particular significance in view of the generally poor chemoresponsiveness of T-cell leukemia/lymphoma. Of note, no apparent toxicity was observed in any treatment
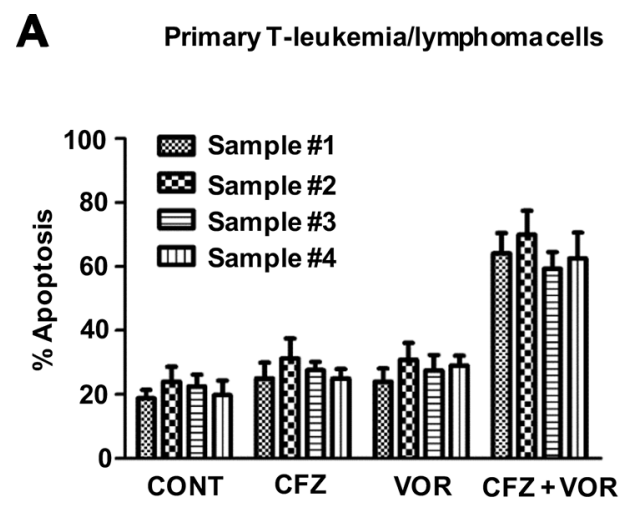

C

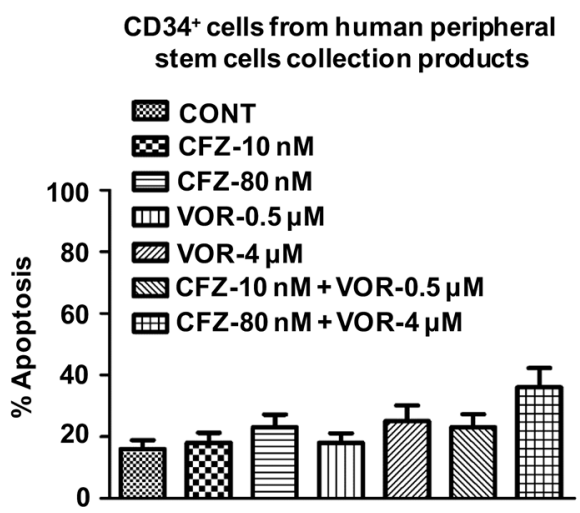

group. Consistent with the mechanism observed in vitro, enhanced p38MAPK and JNK phosphorylation and increased cleavage of PARP were observed in tumor samples obtained from mice treated with carfilzomib and/or vorinostat in vivo. Collectively, our data show that carfilzomib and vorinostat induce apoptosis in T-cell leukemia/lymphoma cells in a highly cooperative manner, and can do so in bortezomib-resistant cells as well as primary tumor cells. We also demonstrate that ROS activates p38MAPK and JNK signaling pathways, further showing an amplification loop between ROS and p38MAPK. Activation of both of these pathways plays a significant role in the functional interaction between carfilzomib and vorinostat (Figure 9). Finally, the ability of

B

Normal T lymphocytes

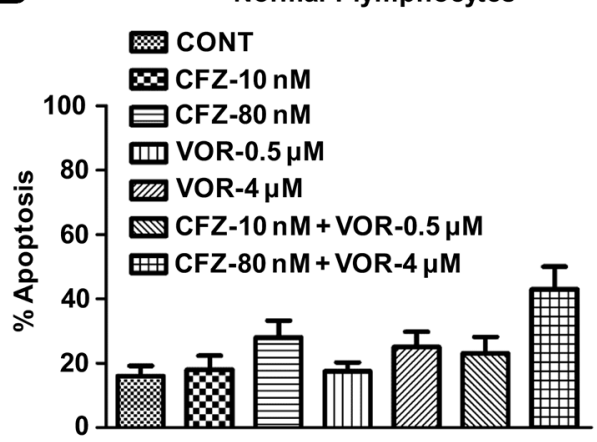

D

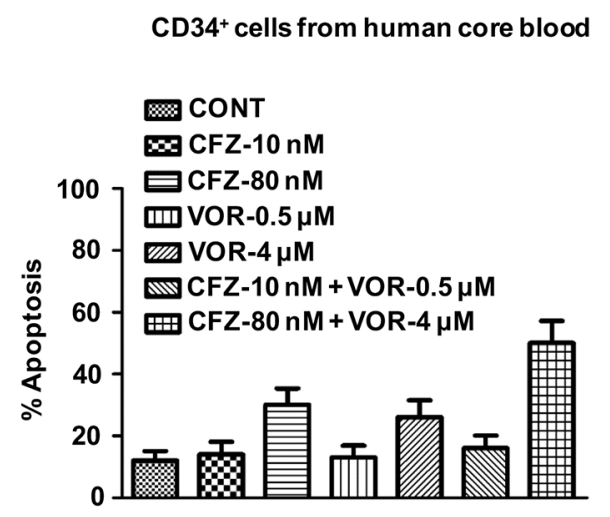

Figure 8: Combination treatment of carfilzomib and vorinostat induces cell apoptosis in human primary T-cell leukemia/lymphoma cells. Primary T-cell leukemia/lymphoma cells (A), normal T lymphocytes from human peripheral blood (B), $\mathrm{CD}_{3}{ }^{+}$cells from peripheral stem cells collection products $(\mathbf{C})$ or human cord blood (D) were treated with indicated concentration of carfilzomib and vorinostat for $48 \mathrm{~h}$, then cell apoptosis was monitored by Annexin V/PI staining.

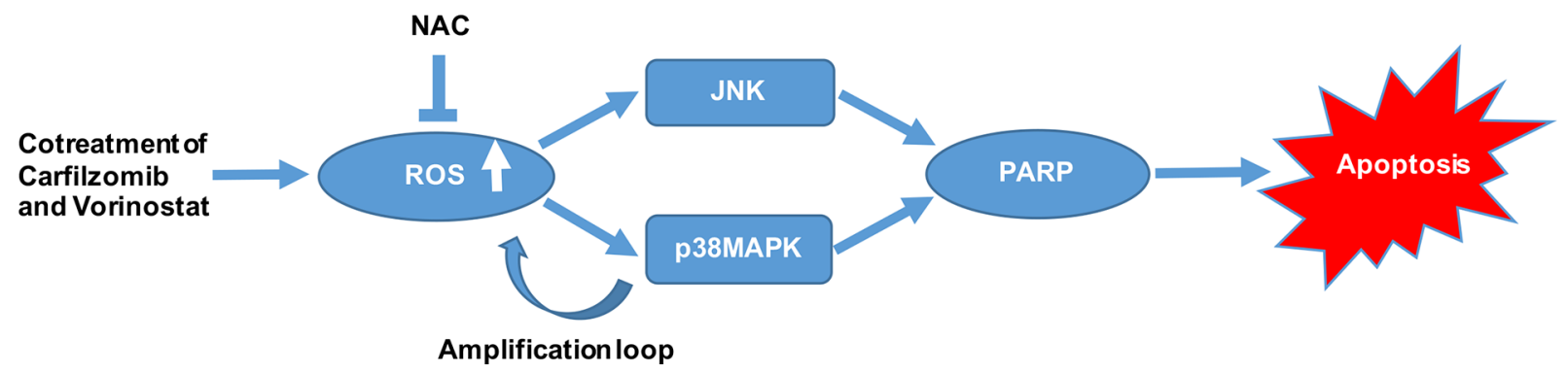

Figure 9: A schematic diagram showing the molecular mechanisms of apoptosis induction by carfilzomib and vorinostat in T-cell leukemia/lymphoma cells. 
carfilzomib/vorinostat to inhibit T-cell leukemia/lymphoma cells growth in an in vivo xenograft model supports further consideration of second-generation proteasome inhibitors and HDACIs use in T-cell leukemia/lymphoma cancers.

\section{MATERIALS AND METHODS}

\section{Cells}

T-cell leukemia (MOLT-4) and lymphoma (HuT 78) cell lines were purchased from the Cell Resource Center of Shanghai Institute for Biological Sciences (Shanghai, China). Bortezomib-resistant MOLT-4 and HuT 78 were obtained by selecting sensitive cells in the presence of nanomolar levels of bortezomib. All cell lines were cultured in RPMI-1640 media (Invitrogen, Frederick, MD), supplemented with 10\% fetal bovine serum (FBS), 1\% penicillin (100 units $/ \mathrm{ml}$ ), and 1\% streptomycin $(100 \mu \mathrm{g} / \mathrm{ml})$. Cells were maintained at $37^{\circ} \mathrm{C}$ in an atmosphere of 5\% $\mathrm{CO}_{2}$ and $95 \%$ air. After informed consent in accordance with the Helsinki Declaration, patient leukemia cells were isolated from the bone marrow of three T-cell leukemia patients and lymphoma cells were obtained from the lymphoma node of one T-cell lymphoma patients. Normal T-lymphocytes were isolated from human peripheral blood using a Pan T Cell Isolation Kit II (Miltenyi Biotec Inc., CA, USA). CD34+ cells were isolated from human peripheral stem cell collection products or human cord blood using CD34 Progenitor Cell Isolation Kit (Miltenyi Biotec Inc., CA, USA). These studies have been approved by the institutional review board of Shanghai Tenth People's Hospital.

\section{Reagents}

Carfilzomib was purchased from Onyx Pharmaceuticals (South San Francisco, CA, USA). Vorinostat was from Merck \& Co., Inc (Rahway, NJ, USA). Bortezomib was from Millennium Pharmaceuticals (Cambridge, MA). N-acetyl-L-cysteine (NAC) was from Sigma-Aldrich (St Louis, MO). The JNK inhibitor SP600125 and p38MAPK inhibitor SB203580 were from Selleckchem (Houston, Tx). The ERK1/2 inhibitor U0126 was from Cell Signaling Technology (Beverly, MA). All other agents except NAC were formulated in dimethyl sulfoxide. NAC was dissolved in double-distilled $\mathrm{H}_{2} \mathrm{O}\left(\mathrm{ddH}_{2} \mathrm{O}\right)$. The mitochondrial membrane potential assay kit with $\mathrm{JC}-1$ and reactive oxygen species assay kit were from Beyotime Institute of Biotechnology (Haimen, China). The Cell Counting Kit-8 (CCK-8) was from Dojindo (Mashikimachi, Japan). The Annexin V/propidium iodide (PI) staining kit was from BD Pharmingen (Franklin Lakes, NJ).

\section{Cell viability and apoptosis assay}

Cell viability was monitored by CCK-8. Alternatively, cell apoptosis was assessed by a flow cytometer with Annexin V/PI staining kit. Annexin V positive cells were considered apoptotic cells. Results of CCK-8 and Annexin V/PI assays were consistent.

\section{Cell cycle analysis}

Cells were suspended with ice-cold PBS, fixed in 70\% ethanol at $-20^{\circ} \mathrm{C}$ for $18 \mathrm{~h}$, after which, cells were washed with PBS and stained for $15 \mathrm{~min}$ at $37^{\circ} \mathrm{C}$ with $500 \mu \mathrm{L}$ of $50 \mu \mathrm{g} / \mathrm{mL}$ propidium iodide (containing $50 \mu \mathrm{g} / \mathrm{mL}$ RNase) (BD Pharmingen) followed by flow cytometric analysis.

\section{Western blot analysis}

Cells were seeded in a 6-well plate at a density of $2 \times 10^{5} / \mathrm{ml}$. Cell lysates were prepared from whole cell pellets. Equal amounts of proteins ( $30 \mu \mathrm{g}$ per lane) were separated on $10 \%$ or $15 \%$ SDS-PAGE, transferred to nitrocellulose membrane, blocked for $1 \mathrm{~h}$ with $5 \%$ milk or $5 \%$ BSA, and probed with primary antibodies overnight at $4{ }^{\circ} \mathrm{C}$. Primary antibodies against various proteins were as follows: anti-phospho (p)-AKT, anti-AKT, anti-(p)JNK, anti-JNK, anti-(p)-ERK1/2, anti-ERK1/2, anti(p)-p38MAPK, anti-p38MAPK, anti-caspase-8, anticaspase- 9 , anti-caspase- 3 , anti-PARP, and anti- $\beta$-actin antibodies. All antibodies were from Cell Signaling Technology (Beverly, MA). Membranes were washed three times for 10 min each with Tween 20-PBS and incubated for $1 \mathrm{~h}$ with Fluorescence-conjugated goat anti-mouse or anti-rabbit IgG secondary antibodies. Membranes were washed with Tween 20-PBS three times for 10 min each and developed using the Odyssey two-color infrared laser imaging system (LI-COR Bioscience, Lincoln, NE). The signal generated by $\beta$-actin was used as an internal control.

\section{Gene silencing}

p38MAPK and JNK targeting oligonucleotide sequences were as follows: p38MAPK shRNA-1, 5'- CAAG GTCTCTGGAGGAATTCA -3'; p38MAPK shRNA-2, 5'-GCACCATGAAGATCAAGATTT -3'; JNK shRNA-1, 5'- GAGTCGGTTAGTCATTGATAG -3'; JNK shRNA-2, 5'- GTGTCTTCAATGTCAACAGAT - $3^{\prime}$; and the shRNA control sequence, 5'- CCTAAGGTTAAGTCGCCCTCG -3'. These sequences were chemically synthesized, used for the cloning of shRNA-encoding sequences, and inserted into a lentiviral vector pLKO.1. $48 \mathrm{~h}$ after co-transfection with psPAX2 packaging plasmid and pMD2.G envelope plasmid into HEK-293T cells using Lipofectamine 2000 (Invitrogen, USA), the media containing lentiviral particles was harvested and used for infection of MOLT-4 cells in presence of $8 \mu \mathrm{g} / \mathrm{ml}$ polybrene (Sigma-Aldrich, St. Louis, MO, USA).

\section{p38MAPK overexpression by plasmid transfection}

The cDNA sequence of p38MAPK was obtained from GenBank (NM_001315.2). It was subcloned into pcDNA3.1 
and confirmed by sequencing. An empty construct pcDNA3.1 was used as a control. Cell transfections were performed using Lipofectamine 2000 reagent (Invitrogen) following the manufacturer's instruction.

\section{Assessment of ROS generation}

Cells were pretreated with or without NAC at $37^{\circ} \mathrm{C}$ for $15 \mathrm{~min}$, then treated with various drugs for the indicated intervals to detect changes in the levels of ROS. Cells were washed with PBS and incubated with $10 \mu \mathrm{M}$ 2', 7'-dichlorodihydrofluorescein diacetate (DCFH-DA) at $37^{\circ} \mathrm{C}$ for $20 \mathrm{~min}$ and fluorescent intensity was assessed using a flow cytometer (BD, Franklin Lakes, NJ).

\section{Analysis of mitochondrial membrane potential}

The loss of mitochondrial membrane potential was monitored by flow cytometry using mitochondrial membrane potential assay kit with $\mathrm{JC}-1$. Cells were washed with PBS and stained with JC-1 dye according to the manufacturer's instructions.

\section{Terminal deoxynucleotidyl transferase-mediated dUTP nick end labeling (TUNEL) assay}

Cell apoptosis in vivo was examined by a terminal deoxynucleotidyl transferase-mediated dUTP nick end labeling (TUNEL) assay as the manufacturer's protocol (Promega, USA). Tumor samples per group were analyzed after the 21 days of treatment.

\section{Animal studies}

Nude mice (4-6 weeks old) were obtained from the Shanghai Laboratory Animal Center (Shanghai, China) and injected subcutaneously with $5 \times 10^{6}$ MOLT- 4 cells into the right flank (day 0). After tumors were visible, the mice received intravenous carfilzomib $(2.0 \mathrm{mg} / \mathrm{kg})$ on days $1,2,8,9,15$ and 16 , intraperitoneal vorinostat $(40 \mathrm{mg} / \mathrm{kg}$ ) on day $1,2,3,8,9,10,15,16$ and 17 or the combination treatment, respectively ( 5 mice per group). Tumor volumes were monitored every other day with calipers and calculated using the formula $0.5 \times a \times b^{2}$ in millimeters, where ' $a$ ' is the long diameter of the tumor and ' $b$ ' is the short diameter of the tumor. Mice body weights were measured periodically as an indicator of toxicity. At the twenty-first day, all mice were sacrificed individually by cervical dislocation. All animal studies have been approved by the institutional review board of Shanghai Tenth People's Hospital.

\section{Statistical analysis}

Data analysis was conducted with SPSS 20.0 software. All data were represented as mean \pm standard deviation (SD). Comparisons among groups were performed using one-way analysis of variance (ANOVA) with the StudentNewman-Keuls post hoc test. A $p$-value less than 0.05 was considered to be statistically significant. All experiments were performed in three or more separate experiments.

\section{ACKNOWLEDGMENTS AND FUNDING}

This study was supported by Grants from the National Natural Science Foundation of China (No. 31271496, 81570190 and 81372391).

\section{CONFLICTS OF INTEREST}

The authors declare no conflicts of interest.

\section{REFERENCES}

1. Koyama D, Kikuchi J, Hiraoka N, Wada T, Kurosawa H, Chiba S, Furukawa Y. Proteasome inhibitors exert cytotoxicity and increase chemosensitivity via transcriptional repression of Notch1 in T-cell acute lymphoblastic leukemia. Leukemia. 2014; 28:1216-1226.

2. Yosifov DY, Kaloyanov KA, Guenova ML, Prisadashka K, Balabanova MB, Berger MR, Konstantinov SM. Alkylphosphocholines and curcumin induce programmed cell death in cutaneous T-cell lymphoma cell lines. Leuk Res. 2014; 38:49-56.

3. Cialfi S, Palermo R, Manca S, Checquolo S, Bellavia D, Pelullo M, Quaranta R, Dominici C, Gulino A, Screpanti I, Talora C. Glucocorticoid sensitivity of T-cell lymphoblastic leukemia/lymphoma is associated with glucocorticoid receptor-mediated inhibition of Notch1 expression. Leukemia. 2013; 27:485-488.

4. Liu H, Chiang MY, Pear WS. Critical roles of NOTCH1 in acute T-cell lymphoblastic leukemia. Int J Hematol. 2011; 94:118-125.

5. Vitagliano $\mathrm{O}$, Addeo R, D'Angelo $\mathrm{V}$, Indolfi $\mathrm{C}$, Indolfi $\mathrm{P}$, Casale F. The Bcl-2/Bax and Ras/Raf/MEK/ERK signaling pathways: implications in pediatric leukemia pathogenesis and new prospects for therapeutic approaches. Expert Rev Hematol. 2013; 6:587-597.

6. Buontempo F, Orsini E, Martins LR, Antunes I, Lonetti A, Chiarini F, Tabellini G, Evangelisti C, Evangelisti C, Melchionda F, Pession A, Bertaina A, Locatelli F, et al. Cytotoxic activity of the casein kinase 2 inhibitor CX-4945 against T-cell acute lymphoblastic leukemia: targeting the unfolded protein response signaling. Leukemia. 2014; 28:543-553.

7. Liu Y, Ge J, Li Q, Gu L, Guo X, Ma ZG, Zhu YP. Anisomycin induces apoptosis of glucocorticoid resistant acute lymphoblastic leukemia CEM-C1 cells via activation of mitogen-activated protein kinases p38 and JNK. Neoplasma. 2013; 60:101-110.

8. Jiang Q, Li F, Shi K, Wu P, An J, Yang Y, Xu C. ATF4 activation by the $\mathrm{p} 38 \mathrm{MAPK}-\mathrm{eIF} 4 \mathrm{E}$ axis mediates apoptosis 
and autophagy induced by selenite in Jurkat cells. FEBS Lett. 2013; 587:2420-2429.

9. Shochat C, Tal N, Bandapalli OR, Palmi C, Ganmore I, te Kronnie G, Cario G, Cazzaniga G, Kulozik AE, Stanulla M, Schrappe M, Biondi A, Basso G, et al. Gain-offunction mutations in interleukin-7 receptor-alpha (IL7R) in childhood acute lymphoblastic leukemias. J Exp Med. 2011; 208:901-908.

10. Zenatti PP, Ribeiro D, Li W, Zuurbier L, Silva MC, Paganin M, Tritapoe J, Hixon JA, Silveira AB, Cardoso BA, Sarmento LM, Correia N, Toribio ML, et al. Oncogenic IL7R gain-of-function mutations in childhood T-cell acute lymphoblastic leukemia. Nat Genet. 2011; 43:932-939.

11. Kouroukis CT, Baldassarre FG, Haynes AE, Imrie K, Reece DE, Cheung MC and Cancer Care Ontario Hematology Disease Site G. Bortezomib in multiple myeloma: a practice guideline. Clin Oncol. 2014; 26:110-119.

12. Mateos MV, Ocio EM, San Miguel JF. Novel generation of agents with proven clinical activity in multiple myeloma. Semin Oncol. 2013; 40:618-633.

13. Zang Y, Thomas SM, Chan ET, Kirk CJ, Freilino ML, DeLancey HM, Grandis JR, Li C, Johnson DE. Carfilzomib and ONX 0912 inhibit cell survival and tumor growth of head and neck cancer and their activities are enhanced by suppression of Mcl-1 or autophagy. Clin Cancer Res. 2012; 18:5639-5649.

14. Herndon TM, Deisseroth A, Kaminskas E, Kane RC, Koti KM, Rothmann MD, Habtemariam B, Bullock J, Bray JD, Hawes J, Palmby TR, Jee J, Adams W, et al. U.s. Food and Drug Administration approval: carfilzomib for the treatment of multiple myeloma. Clin Cancer Res. 2013; 19:4559-4563.

15. Sharma NL, Groselj B, Hamdy FC, Kiltie AE. The emerging role of histone deacetylase (HDAC) inhibitors in urological cancers. BJU Int. 2013; 111:537-542.

16. Hrabeta J, Stiborova M, Adam V, Kizek R, Eckschlager T. Histone deacetylase inhibitors in cancer therapy. A review. Biomed Pap Med Fac Univ Palacky Olomouc Czech Repub. 2014; 158:161-169.

17. Duvic M, Vu J. Vorinostat: a new oral histone deacetylase inhibitor approved for cutaneous T-cell lymphoma. Expert Opin Investig Drugs. 2007; 16:1111-1120.

18. Hui KF, Lam BH, Ho DN, Tsao SW, Chiang AK. Bortezomib and SAHA synergistically induce ROS-driven caspase-dependent apoptosis of nasopharyngeal carcinoma and block replication of Epstein-Barr virus. Mol Cancer Ther. 2013; 12:747-758.

19. Jiang Y, Wang Y, Su Z, Yang L, Guo W, Liu W, Zuo J. Synergistic induction of apoptosis in HeLa cells by the proteasome inhibitor bortezomib and histone deacetylase inhibitor SAHA. Mol Med Rep. 2010; 3:613-619.

20. Pitts TM, Morrow M, Kaufman SA, Tentler JJ, Eckhardt SG. Vorinostat and bortezomib exert synergistic antiproliferative and proapoptotic effects in colon cancer cell models. Mol Cancer Ther. 2009; 8:342-349.
21. Bastian L, Hof J, Pfau M, Fichtner I, Eckert C, Henze G, Prada J, von Stackelberg A, Seeger K, Shalapour S. Synergistic activity of bortezomib and HDACi in preclinical models of B-cell precursor acute lymphoblastic leukemia via modulation of p53, PI3K/AKT, and NF-kappaB. Clin Cancer Res. 2013; 19:1445-1457.

22. Dai Y, Chen S, Wang L, Pei XY, Kramer LB, Dent P, Grant S. Bortezomib interacts synergistically with belinostat in human acute myeloid leukaemia and acute lymphoblastic leukaemia cells in association with perturbations in NFkappaB and Bim. Br J Haematol. 2011; 153:222-235.

23. Wang AH, Wei L, Chen L, Zhao SQ, Wu WL, Shen ZX, Li JM. Synergistic effect of bortezomib and valproic acid treatment on the proliferation and apoptosis of acute myeloid leukemia and myelodysplastic syndrome cells. Ann Hematol. 2011; 90:917-931.

24. Sato A, Asano T, Ito K, Asano T. Vorinostat and bortezomib synergistically cause ubiquitinated protein accumulation in prostate cancer cells. J Urol. 2012; 188:2410-2418.

25. Asklund T, Kvarnbrink S, Holmlund C, Wibom C, Bergenheim T, Henriksson R, Hedman H. Synergistic killing of glioblastoma stem-like cells by bortezomib and HDAC inhibitors. Anticancer Res. 2012; 32:2407-2413.

26. Gatti L, Benedetti V, De Cesare M, Corna E, Cincinelli R, Zaffaroni N, Zunino F, Perego P. Synergistic interaction between the novel histone deacetylase inhibitor ST2782 and the proteasome inhibitor bortezomib in platinum-sensitive and resistant ovarian carcinoma cells. J Inorg Biochem. 2012; 113:94-101.

27. Hideshima T, Richardson PG, Anderson KC. Mechanism of action of proteasome inhibitors and deacetylase inhibitors and the biological basis of synergy in multiple myeloma. Mol Cancer Ther. 2011; 10:2034-2042.

28. Fostier K, De Becker A, Schots R. Carfilzomib: a novel treatment in relapsed and refractory multiple myeloma. Onco Targets Ther. 2012; 5:237-244.

29. Kuhn DJ, Chen Q, Voorhees PM, Strader JS, Shenk KD, Sun CM, Demo SD, Bennett MK, van Leeuwen FW, Chanan-Khan AA, Orlowski RZ. Potent activity of carfilzomib, a novel, irreversible inhibitor of the ubiquitinproteasome pathway, against preclinical models of multiple myeloma. Blood. 2007; 110:3281-3290.

30. Paoluzzi L, Gonen M, Gardner JR, Mastrella J, Yang D, Holmlund J, Sorensen M, Leopold L, Manova K, Marcucci G, Heaney ML, O'Connor OA. Targeting Bcl-2 family members with the $\mathrm{BH} 3$ mimetic AT-101 markedly enhances the therapeutic effects of chemotherapeutic agents in in vitro and in vivo models of B-cell lymphoma. Blood. 2008; 111:5350-5358.

31. Lue J, Goel S, Mazumder A. Carfilzomib for the treatment of multiple myeloma. Drugs Today (Barc). 2013; 49: 171-179.

32. Dasmahapatra G, Lembersky D, Son MP, Attkisson E, Dent P, Fisher RI, Friedberg JW, Grant S. Carfilzomib interacts synergistically with histone deacetylase inhibitors 
in mantle cell lymphoma cells in vitro and in vivo. Mol Cancer Ther. 2011; 10:1686-1697.

33. Dasmahapatra G, Lembersky D, Kramer L, Fisher RI, Friedberg J, Dent P, Grant S. The pan-HDAC inhibitor vorinostat potentiates the activity of the proteasome inhibitor carfilzomib in human DLBCL cells in vitro and in vivo. Blood. 2010; 115:4478-4487.

34. Gao M, Gao L, Tao Y, Hou J, Yang G, Wu X, Xu H, Tompkins VS, Han Y, Wu H, Zhan F, Shi J. Proteasome inhibitor carfilzomib interacts synergistically with histone deacetylase inhibitor vorinostat in Jurkat T-leukemia cells. Acta Biochim Biophys Sin (Shanghai). 2014; 46:484-491.

35. Dasmahapatra G, Patel H, Friedberg J, Quayle SN, Jones SS, Grant S. In vitro and in vivo interactions between the HDAC6 inhibitor ricolinostat (ACY1215) and the irreversible proteasome inhibitor carfilzomib in non-Hodgkin lymphoma cells. Mol Cancer Ther. 2014; 13:2886-2897.

36. Zhang QL, Wang L, Zhang YW, Jiang XX, Yang F, Wu WL, Janin A, Chen Z, Shen ZX, Chen SJ, Zhao WL. The proteasome inhibitor bortezomib interacts synergistically with the histone deacetylase inhibitor suberoylanilide hydroxamic acid to induce T-leukemia/lymphoma cells apoptosis. Leukemia. 2009; 23:1507-1514.

37. Emanuele S, Lauricella M, Carlisi D, Vassallo B, D'Anneo A, Di Fazio P, Vento R, Tesoriere G. SAHA induces apoptosis in hepatoma cells and synergistically interacts with the proteasome inhibitor Bortezomib. Apoptosis. 2007; 12:1327-1338.

38. Pei XY, Dai Y, Grant S. Synergistic induction of oxidative injury and apoptosis in human multiple myeloma cells by the proteasome inhibitor bortezomib and histone deacetylase inhibitors. Clin Cancer Res. 2004; 10:3839-3852.

39. Miller CP, Ban K, Dujka ME, McConkey DJ, Munsell M, Palladino M, Chandra J. NPI-0052, a novel proteasome inhibitor, induces caspase- 8 and ROS-dependent apoptosis alone and in combination with HDAC inhibitors in leukemia cells. Blood. 2007; 110:267-277.

40. Yu C, Rahmani M, Dent P, Grant S. The hierarchical relationship between MAPK signaling and ROS generation in human leukemia cells undergoing apoptosis in response to the proteasome inhibitor Bortezomib. Exp Cell Res. 2004; 295:555-566.

41. Premkumar DR, Jane EP, Agostino NR, DiDomenico JD, Pollack IF. Bortezomib-induced sensitization of malignant human glioma cells to vorinostat-induced apoptosis depends on reactive oxygen species production, mitochondrial dysfunction, Noxa upregulation, Mcl-1 cleavage, and DNA damage. Mol Carcinog. 2013; 52:118-133.
42. Heider U, von Metzler I, Kaiser M, Rosche M, Sterz J, Rotzer S, Rademacher J, Jakob C, Fleissner C, Kuckelkorn U, Kloetzel PM, Sezer O. Synergistic interaction of the histone deacetylase inhibitor SAHA with the proteasome inhibitor bortezomib in mantle cell lymphoma. Eur J Haematol. 2008; 80:133-142.

43. Heider U, Rademacher J, Lamottke B, Mieth M, Moebs M, von Metzler I, Assaf C, Sezer O. Synergistic interaction of the histone deacetylase inhibitor SAHA with the proteasome inhibitor bortezomib in cutaneous T cell lymphoma. Eur J Haematol. 2009; 82:440-449.

44. Denlinger CE, Rundall BK, Jones DR. Proteasome inhibition sensitizes non-small cell lung cancer to histone deacetylase inhibitor-induced apoptosis through the generation of reactive oxygen species. J Thorac Cardiovasc Surg. 2004; 128:740-748.

45. Chauhan D, Singh A, Brahmandam M, Podar K, Hideshima T, Richardson P, Munshi N, Palladino MA, Anderson KC. Combination of proteasome inhibitors bortezomib and NPI0052 trigger in vivo synergistic cytotoxicity in multiple myeloma. Blood. 2008; 111:1654-1664.

46. Sakamoto T, Ozaki K, Fujio K, Kajikawa SH, Uesato S, Watanabe K, Tanimura S, Koji T, Kohno M. Blockade of the ERK pathway enhances the therapeutic efficacy of the histone deacetylase inhibitor MS-275 in human tumor xenograft models. Biochem Biophys Res Commun. 2013; 433:456-462.

47. Ozaki K, Minoda A, Kishikawa F, Kohno M. Blockade of the ERK pathway markedly sensitizes tumor cells to HDAC inhibitor-induced cell death. Biochem Biophys Res Commun. 2006; 339:1171-1177.

48. Ozaki K, Kosugi M, Baba N, Fujio K, Sakamoto T, Kimura S, Tanimura S, Kohno M. Blockade of the ERK or PI3KAkt signaling pathway enhances the cytotoxicity of histone deacetylase inhibitors in tumor cells resistant to gefitinib or imatinib. Biochem Biophys Res Commun. 2010; 391: 1610-1615.

49. Cascone T, Morelli MP, Morgillo F, Kim WY, Rodolico G, Pepe S, Tortora G, Berrino L, Lee HY, Heymach JV, Ciardiello F. Synergistic anti-proliferative and pro-apoptotic activity of combined therapy with bortezomib, a proteasome inhibitor, with anti-epidermal growth factor receptor (EGFR) drugs in human cancer cells. J Cell Physiol. 2008; 216:698-707. 